\title{
PERANCANGAN POSTER PENCEGAHAN PENYEBARAN HOAX SEBAGAI INFORMASI YANG MENYESATKAN PUBLIK
}

\author{
Fachrul Rozi ${ }^{1)}$, Bambang Gunawan ${ }^{2)}$, Kartika Puji Lestari ${ }^{3)}$ \\ Program Studi Desain Komunikasi Visual \\ Fakultas Bahasa dan Seni Universitas Indraprasta PGRI \\ Jl. Nangka No. 58c, Tanjung Barat, Jakarta Selatan, 12530, Indonesia \\ fachrulroziozi@gmail.com
}

\begin{abstract}
Abstrak
Tujuan perancangan poster ini untuk pencegahan informasi palsu atau hoax dengan menggunakan desain dan bahasa yang tepat, agar bermanfaat dan tepat sasaran. Hasil dari perancangan ini adalah sebuah poster tentang pencegahan penyebaran hoax. Konsep desain dan ilustrasi yang diterapkan adalah gaya ilustrasi realistis, gambar dibuat seperti aslinya sesuai anatomi dan proporsinya. Penggunaan huruf pada poster ini lebih mengutamakan huruf yang tingkat keterbacaannya tinggi. Oleh karena itu, dipilihlah jenis huruf sans-serif bernama Impact untuk judul dan Myriad Pro untuk keterangan lain. Huruf sans-serif adalah huruf yang tidak memiliki kait/ kaki dan secara kontur hurufnya, huruf ini lebih modern dibanding huruf yang memiliki serif/kait/kaki. Proses perancangan poster ini menggunakan aplikasi Adobe Illustrator. Untuk layout menggunakan Picture Window Layout di mana jenis ini, tampilan gambar yang besar menjadi suatu keutamaan dan keterangan gambar yang besar sehingga masih bisa dibaca dengan baik. Penggunaan media poster ini diharapkan dapat mengedukasi masyarakat agar lebih berhati-hati sebelum menyebarkan informasi yang belum teridentifikasi kebenarannya, sebelum menyebarkan informasi tersebut.
\end{abstract}

Kata Kunci: Hoax, Poster, Desain

\begin{abstract}
The purpose of designing this poster for the prevention of false information or hoaxes using the right design and language, to be useful and on target. The result of this design is a poster about the prevention of hoax deployments. The concept of design and illustration applied is a realistic style of illustration, the image is made like the original according to its anatomy and proportions. The use of letters on this poster is more of a letter that is a high reading level. Therefore, a sansserif typeface is chosen as Impact for the title and Myriad Pro for other information. Sans-serif letters are letters that do not have hooks/feet and contoured letters, they are more modern than letters that have serif/hook/foot. This poster design process uses Adobe Illustrator application. For layouts using the Picture Window Layout where this type, a large image display becomes a great priority and Image caption So it can still be read well. The use of media posters is expected to educate people to be more cautious before disseminating information that has not been identified, before spreading the information.
\end{abstract}

Keywords: Hoax, Poster, Design

Correspondence author: Name, E-mail, City, and Country 


\section{PENDAHULUAN}

Persebaran informasi dalam beberapa tahun terakhir ini sangat cepat melalui berbagai media cetak maupun elektronik. Hadirnya media sosial dan aplikasi pesan singkat (chat) yang didukung fitur like and share menjadi media favorit karena memudahkan orang untuk membaca dan menyebarkan informasi sehingga beragam informasi mudah diperoleh dan disebarluaskan dalam waktu singkat (Tashandra, 2017). Namun, tidak banyak berita yang tersebar adalah berita bohong atau yang dikenal dangan sebutan hoax.

Dalam bahasa Inggris, definisi kata hoax adalah "deliberately fabricated falsehood made to masquerade as truth", yang berarti sebuah kebohongan yang secara sengaja dibuat dan "menyamar" seolah berita itu adalah sebuah kebenaran (Juliswara dalam Sinaga, 2017:122).

Hoax bukan sesuatu yang baru dan sudah banyak beredar sejak Johannes Gutenberg menemukan mesin cetak pada tahun 1439. Zaman sekarang seiring majunya teknologi dan internet yang membuat seseorang dapat dengan mudah menerima maupun membuat pesan, persentase hoax melesat naik dan otomatis menimbulkan situasi tidak kondusif dalam kehidupan sosial masyarakat. Terdapat 3 kategori hoax, yaitu: (1) Proper Hoax, yaitu berita yang murni sengaja disusun untuk menyesatkan dan menipu pembacanya; (2) Yay Headline, Nay Content, yaitu berita yang memiliki headline yang sangat menarik dan membangkitkan keingintahuan, tetapi kontras dengan kualitas konten yang dikandungnya; (3) Same News, Different Context, yaitu berita yang faktual, tetapi memiliki detail yang diubah sehingga tidak sesuai dengan fakta, misalnya tanggal dan lokasi (Hurlock dalam Sinaga, 2018:122).

Hoax menjadi suatu hal yang meresahkan dan menyesatkan mayoritas masyarakat yang menerima berita baik melalui verbal maupun visual, tetapi seringkali sumber berita tidak kredibel justru menjadi sarana utama penyebaran hoax. Dampak terburuk dari hoax yang akan terjadi adalah terpecahbelahnya kesatuan bangsa melalui isu SARA. Hoax sendiri sebenarnya bukanlah sesuatu hal yang sulit untuk dilawan apabila masyarakat memiliki pengetahuan literasi media, yaitu sikap kritis terhadap informasi yang menjadikan masyarakat dapat lebih kritis menyaring berita yang tersebar di media massa. Oleh karena itu, perlu dibuat perancangan poster mengenai hoax sebagai informasi yang menyesatkan publik kepada masyarakat di kota-kota besar maupun kecil di Indonesia.

\section{METODE PENELITIAN}

Pada penelitian ini digunakan metode deskriptif kualitatif. Dimana peneliti berusaha menggambarkan dan mendeskripsikan tentang kasus hoax beberapa waktu lalu. Data yang telah didapat kemudian dianalisis dengan pendekatan Framing, yaitu metode pembingkaian yang fokus dalam menganalisis pokok masalah tentang hoax dengan menyajikan realita yang terjadi di lapangan. Penelitian ini berusaha untuk menafsirkan data yang ada yang kemudian dirancang menjadi sebuah poster pencegahan Hoax.

\section{HASIL DAN PEMBAHASAN}

\section{Media dan Hoax}

Pada kemajuan teknologi informasi komunikasi saat ini tidak hanya memberikan dampak yang positif tetapi juga memberikan dampak yang buruk. Penyampaian akan informasi begitu cepat tersebut melalui beberapa media sosial seperti facebook, twitter, ataupun pesan telepon genggam seperti, whatsapp, dan sebagainya yang tidak dapat di filter dengan baik.

Informasi yang dikeluarkan baik orang perorang maupun badan usaha melalui media sosial dan elektronik ketika telah terkirim dan dibaca oleh banyak orang dapat memengaruhi emosi, perasaan, pikiran bahkan tindakan seseorang atau kelompok, apalagi dengan judul yang terlalu heboh yang membuat penerima tidak membaca isi konten informasi melainkan langsung menyebarkan informasi tersebut kepada orang lain. Sangat disayangkan apabila informasi yang disampaikan tersebut adalah informasi yang tidak akurat, terlebih informasi tersebut adalah informasi bohong (hoax) dengan judul yang sangat provokatif mengiring pembaca dan penerima kepada opini yang negatif. 


\section{Perancangan Poster}

Berikut merupakan konsep media yang digunakan dalam perancangan poster tentang pencegahan penyebaran hoax sebagai informasi yang menyesatkan publik. Pada proses perancangan poster ini, pembuatannya menggunakan suatu aplikasi yaitu Adobe Illustrator. Dengan ukuran kertas A4 atau 21 x 29,7 cm. Ukutan font meyesuaikan tingkat keterbacaan pada poster. Untuk pewarnaan menggunakan metode CMYK.

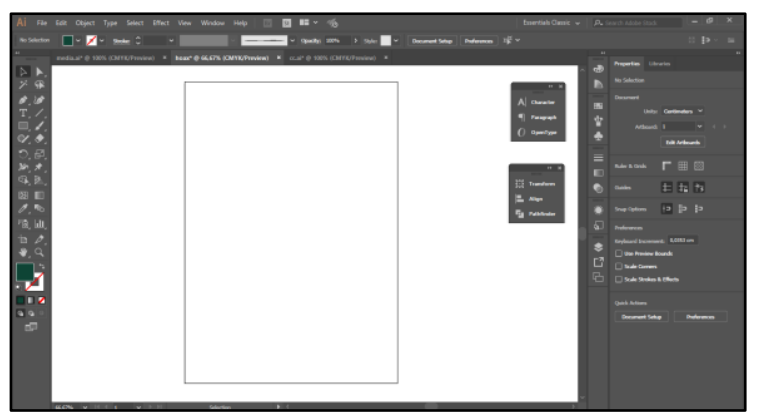

Gambar 1 Tampilan Interface Software Adobe Illustrator

Tipografi

Menurut Kusrianto (dalam Rosita, 2014:63) definisi tipografi adalah sebagai suatu proses seni menyusun bahan publikasi menggunakan huruf cetak hingga merangkainya dalam sebuah komposisi yang tepat untuk memperoleh suatu efek tampilan yang di kehendaki.

Penggunaan huruf pada poster ini lebih mengutamakan readability (keterbacaan sebuah huruf). Oleh karena itu, penulisan memilih jenis huruf Impact. Pada jenis huruf Impact adalah jenis huruf sans serif yang tidak memiliki kait atau kaki.

\section{A B CDEFGHIJIMNOPQRSTUVW KYZ abcdefghijImnopurstuvw $x$ yz 1234567890

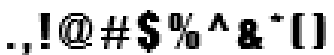

Gambar 2 Font Impact

Font tersebut digunakan pada bagian judul dan subjudul agar terlihat lebih jelas dan tingkat keterbacaan yang tinggi. Sementara untuk bagian keterangan menggunakan font bernama Myriad Pro.

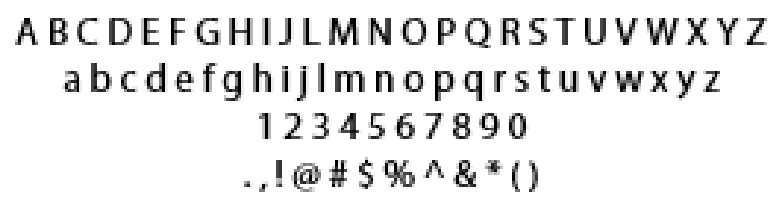

Gambar 3 Font Myriad Pro

Warna

Warna merupakan elemen yang sangat penting karena warna dapat memberikan efek cahaya yang memberikan kesan pada mata sehingga dapat menghadirkan karakter dari suatu bentuk yang secara psikologis mempengaruhi perasaan (Wayan, 2010). Warna yang akan digunakan pada poster ini menggunakan warna hitam, merah, dan putih serta turunan pada warna tersebut, kemudian bagian latar belakang menggunakan warna kuning, tetapi yang mendominasi warna putih pada ilustrasi baju. Penggunaan warna ini ditunjukan untuk kalangan anak muda baik laki 
laki dan perempuan dan warna lebih mendominasi oleh warna soft atau lembut. Warna pada huruf sub judul menggunakan warna merah agar khalayak yang dituju mengerti maksud dari judul utama poster tersebut.

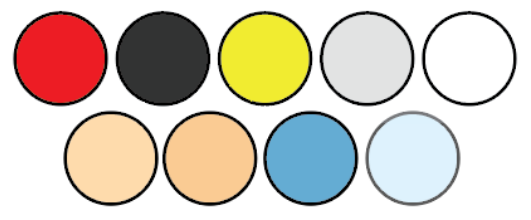

Gambar 4 Warna pada Poster

\section{Ilustrasi}

Ilustrasi adalah hasil visualisasi dari satu tulisan dengan teknik drawing, lukisan, fotografi, atau teknik seni rupa lainnya yang lebih menekankan hubungan subjek dengan tulisan yang dimaksud daripada bentuk (Subianto, 2018:219). Gaya ilustrasi yang coba ditarapkan pada poster ini adalaha gaya realis, di mana gambar yang dibuat seperti aslinya sesuai anatomi dan proporsinya.

Dalam merancang poster ini, peneliti membuat ilustrasi seorang manusia yang sedang menggunakan smartphone yang dihadapkan mendapatkan situasi belum diketahuinya kebenarannya bahwa berita itu palsu atau berita asli. Judul diletakan di atas dan dibuat lebih besar agar khalayak membaca pesan yang ingin disampaikan. Kemudian diberikan subjudul sebagai penegas dari maksud poster tersebut. Serta dibuat juga keterangan lain berdasarkan fakta fakta yang didapat oleh penulis. Penulis menambahkan tagar \#LAWANHOAX agar khalayak ikut meyebarkan dan mencegah penyebaran berita palsu atau hoax.

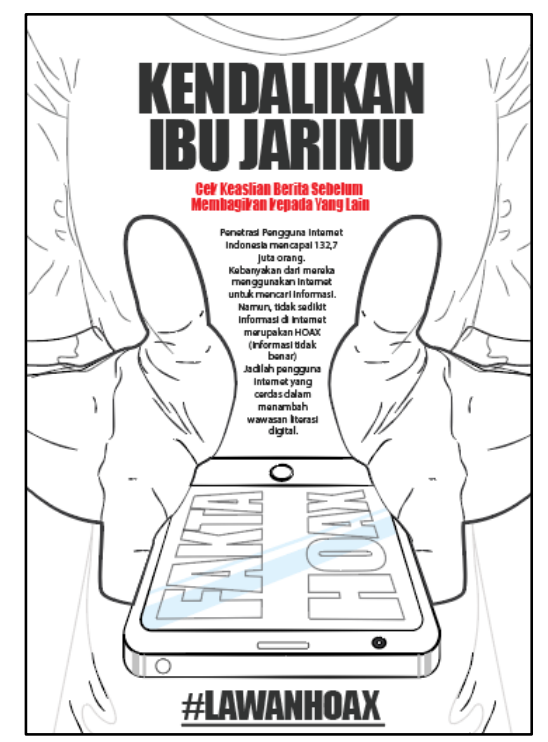

Gambar 5 Hasil dari Tracing Gambar Digital

Kemudian, penulis membuat ilustrasi malaikat dan iblis pada bagian ibu jari di ilustrasi tersebut. Penggunaan ilustrasi malaikat dan iblis diilustrasikan agar menjadi representasi dari baik dan jahat. 


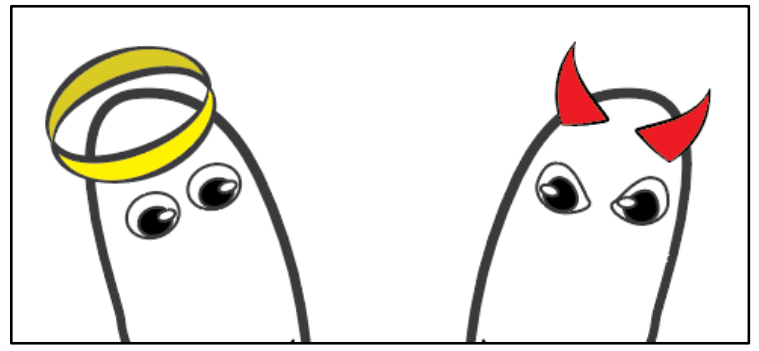

Gambar 6 Ilustrasi Malaikat dan Iblis

\section{Hasil Perancangan}

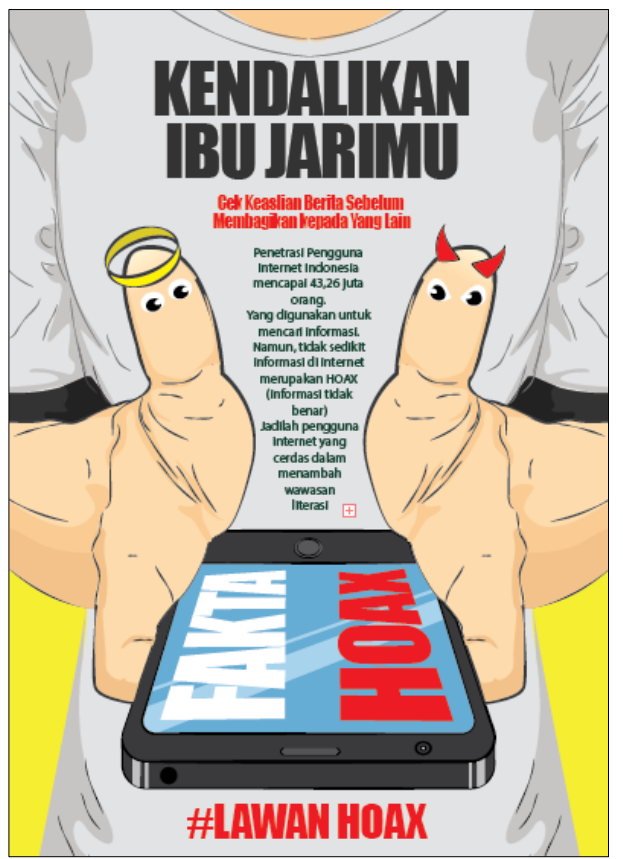

Gambar 7 Hasil Poster Tentang Pencegahan Penyebaran Informasi Hoax

\section{SIMPULAN}

Berdasarkan hasil dari pembahasan tersebut dapat ditarik simpulan, bahwa ilustrasi yang coba diterapkan pada poster ini adalah gaya ilustrasi realist, di mana gambar yang dibuat seperti aslinya sesuai anatomi dan poporsinya yang dapat diterapkan untuk menginformasikan kepada khalayak dalam berhati-hati dalam menyebarkan informasi yang belum dikatahui kebenarannya. Huruf yang digunakan adalah jenis huruf Sans-Serif, yaitu Impact dan huruf Myriad Pro. Menggunakan warna hitam, merah dan putih pada font. Proses perancangan menggunakan aplikasi Adobe Illustrator. Diharapakan poster ini dapat mengedukasi masyarakat tentang berhati-hati dalam menggunakan smartphone dan menyebarkan informasi.

\section{DAFTAR PUSTAKA}

Rosita, D. Q. (2016). Perancangan tipografi asimilasi aksara latin karakteristik ondel-ondel sebagai solusi kreatif melestarikan budaya betawi. Jurnal Desain, 2(02), 61-68.

Sinaga, C. P. J., \& Yonatia, J. (2018). Kampanye Penangkalan Hoax Melalui Aplikasi Gawai. Serat Rupa Journal of Design, 2(2), 119-129. 
Subianto, I. B., Anto, P., \& Akbar, T. (2018). Perancangan poster sebagai media edukasi peserta didik. Jurnal Desain, 5(03), 215-222.

Tashandra, N. (2017).Media Sosial, Penyebar "Hoax", dan Budaya Berbagi. [Online]. Diakses dari: $\quad$ https://nasional.kompas.com/read/2017/02/14/09055481/media.sosial. penyebaran.hoax.dan.budaya.berbagi.

I Wayan, G. (2010). Pengertian Warna dan Tekstur. Artikel Bulan Juni 2010, 8, 1-1. 